\title{
The addiction drugs and hyponatremia
}

\section{Introduction}

- Till 1890, Cocaine, Cannabis and Heroin were available freely in US.

- In Britain, Dr. Thomas Cloustan pointed to “Addiction" in 1890.

- In America Dr. Jansen Mattison also pointed to the same.

- During First World War, many international Conferences were met to restrict addictive drugs in 1909 in Shanghai Conference, Narcotics were banned.

- By 1920, most American States had outlawed Narcotics and prohibited use of Alcohol called as Prohibition.

- But at those times any new drug could be invented lawfully.

- In 1920 itself, Amphetamine was invented.

- In 1933 President Roosevelt signed the amendment to make use of alcohol legal.

- By late 1940 amphetamine was used as recreational drug.

- In 1950 legislations of USA started banning Amphetamine and Methylene Doixy Meth Amphetamine (MDMA or Ecstasy) by 1985.

- In 1960, hallucinogenic drugs like LSD (Lysergic acid Diethylamide) and Mescaline came into being.

- Mescaline was banned in 1970.

- Now in our State many school children are targeted by Drug people and many children are caught unaware about these drugs.

- So we need to educate them about these drugs as they are becoming more available.

\section{Sodium}

- One mechanism through which drugs act is by lowering body sodium levels. This will delay the evacuation of dopamine which is released and they get a high.

- As global temperature is slowly going on a rise, people in the tropical region are susceptible to lose sodium and there is a need to ensure that these people take dietary sodium to remain normal.

- The last five years we saw the 'Kanikonna' flowering in the December. Usually it blossoms during April. As the hot climate was similar to the one in April the flower also blossommed at a different time. We also witnessed rain in December. Always rain come in hot seasons.

- The English and the West have to consume some amount of alcohol in the evenings in order to lose some sodium as they have very little Sun during winter.

- We in South India have enough Sun to cause a decrease in our body sodium so that we needn't resort to any alcohol to get the
Volume 8 Issue 2 - 2020

Niranjan Prasad

Department of Psychiatry, DMWIMS Medical College, India

Correspondence: Dr Niranjan Prasad, Department of Psychiatry, DMWIMS Medical College, Wayanad, Kerala, India, Email niranjan.prasad@dmwims.com

Received: February 05, 2020 | Published: April 30, 2020

body sodium to a lower level. We may sometimes need to raise the sodium to the required level.

- When a person becomes hyponatremic, and when someone gives him something he cannot refuse it. So if that something is a drug there is a chance for first use. As this again lowers sodium he gets a high and wants to do it once more. So we need to make ourselves with enough sodium. ${ }^{1}$

- People have a belief that consuming sodium increases BP. But it is not always true. If a person has $100 / 70 \mathrm{~mm} \mathrm{Hg} \mathrm{BP,} \mathrm{it}$ means that he can excrete sodium with that BP. As he gets older BP goes up like 110/70, 120/80 and then 130/90mm Hg. That means body can give out sodium only when BP is that much. But if the person is not taking in sodium at all then from where do his kidneys get enough sodium to take back glucose from the filtered urine. It is at this time, kidneys start raising the BP through Renin Angiotensin system. If a person has $200 / 100 \mathrm{~mm}$ Hg BP, his BP will go down to 130/90 by taking sodium.,3

- Some of the addictive drugs are hyponatremic, almost all antideppressants are also hyponatremic. Now almost all drugs coming from the West are also hyponatremic. For eg. Levitracitam is an anticonvulsant drug but it has hyponatremic effect. Drug used in cardiology are also reduce sodium. Newer psychiatric drugs like Lurazedone and Vilazedone are also reducing sodium faster than previously used antipsychotic drugs. $^{4}$

- Most doctors do not look Sodium Potassium level. I have come across people who have done almost all tests available, from Mangalore but they just missed doing Sodium potassium test.

- Febrile illness cause hyper metabolism to produce fever. For normal metabolism some amount os sodium is necessary. When it becomes hyper more sodium is used leading to low level. So most people do not take food for two days after a febrile illness, only because of low sodium.

- Many foods also use more sodium for eg rice needs more sodium. Fishes like mackeral and chicken need more sodium.

- Decreased Sodium lead to non absorption of things from stomach and intestine. I have seen hyponatremic patients having anemia. Some others had hypocalcemia. 
- This should be an eye opener for all and we need to be more conscious about our own sodium level.

\section{Acknowledgments}

None.

\section{Conflicts of interest}

The author declares there are no conflicts of interest.

\section{References}

1. Androgue H, Madias NE. The challenge of hyponatremia. $J$ Am Soc Nephrol. 20121;23(7):1140-1148.
2. Liamis G, Rodenburg EM, Hofman A, et al. Electrolyte Disorders in community subjects-Prevalence \& Risk Factors. $\mathrm{Am} \mathrm{J} \mathrm{Med.}$ 2013;126(3):256-263.

3. Liamis G, Tsimihodimos V, Ellisa M. Hyponatremia in Diabetes Mellitus. Journal of Diabetes \& Metabolism. 2015;6:560.

4. Verbasis TG, Goldsmith SR, Greenbag A, et al. Diagnosis, Evaluation and Treatment of hyponatremia , Expert panel recommendations. Am J Med. 2013;126(10 Suppl 1):S1-42. 